\title{
ESTRATÉGIAS PARA RESOLUÇÃO DOS PRINCIPAIS DESAFIOS DA LOGÍSTICA DE PRODUTOS AGRÍCOLAS EXPORTADOS PELO BRASIL ${ }^{1}$
}

\author{
Bruno Rógora Kawano ${ }^{2}$ \\ Giana de Vargas Mores $^{3}$ \\ Roberto Fray da Silva ${ }^{4}$ \\ Carlos Eduardo Cugnasca ${ }^{5}$
}

\begin{abstract}
Resumo: O Brasil é um dos maiores produtores e exportadores de produtos agrícolas do mundo. Este artigo buscou identificar e sugerir ações corretivas para os principais desafios que impactam na competitividade das cadeias brasileiras de produtos agrícolas voltados para a exportação. Alguns desafios foram identificados na literatura, considerando a necessidade de: análise das cadeias agrícolas; coordenação entre os elos de cada cadeia; melhoria nas metodologias utilizadas para a otimização das cadeias agrícolas; existência de sistemas de rastreabilidade satisfatórios que englobem toda a cadeia; e considerações em relação à infraestrutura do atual agronegócio brasileiro. Algumas ações foram propostas para auxiliar na eliminação desses gargalos, como: separação dos produtos por categorias de acordo com o equipamento de transporte utilizado; fomento da coordenação entre os elos das cadeias; utilização de softwares específicos; elaboração de sistemas de rastreabilidade; utilização de parcerias públicoprivadas para melhorar a qualidade da atual malha viária; e a consequente redução dos custos com transporte dos produtos agropecuários.
\end{abstract}

Palavras-chave: Logística agroindustrial; Cadeia de suprimentos; Competitividade.

1 Recebido em: 23/02/2012; Aceito em: 4/05/2012.

2 Engenheiro agrônomo, mestrando em Planejamento de Sistemas Energéticos pela Universidade Estadual de Campinas. E-mail: brkawano@yahoo.com.br.

3 Bacharel em Ciências Econômicas, mestranda em Agronegócios pela Universidade Federal do Rio Grande do Sul.E-mail: gimores@gmail.com.

4 Engenheiro agrônomo pela Universidade de São Paulo. E-mail: roberto.fray.silva@gmail.com.

5 Engenheiro elétrico, Doutor em Engenharia Elétrica pela Universidade de São Paulo. Professor associado do Departamento de Engenharia de Computação e Sistemas Digitais da Escola Politécnica da Universidade de São Paulo.E-mail: cecugnas@usp.br. 
Abstract: Brazil is one of the world's biggest producers and exporters of agricultural products. This paper sought to identify and suggest solutions for the main challenges that impact on Brazilian chains of agricultural products for exportation purposes. Some challenges were identified in the literature, considering the need for: analysis of agricultural chains; coordination between the links of each chain; improvement in the methodologies used for optimization of agricultural chains; existence of satisfactory traceability systems covering the whole chain; considerations in relation to the infrastructure of the current Brazilian agribusiness. Some actions were proposed to help in the elimination of these bottlenecks, such as: separation of products by categories according to transport equipment used; fostering coordination between the links of the chains; use of specific software; development of traceability systems; use of public-private partnerships to improve the quality of the current road network and the consequent reduction of transportation costs of agricultural products.

Key words: Agroindustrial logistics; Supply chain; Competitiveness.

\section{Introdução}

O Brasil é um dos líderes mundiais na produção e exportação de produtos agropecuários. Dados do Ministério da Agricultura (BRASIL, 2012) confirmam que o país é maior produtor e exportador mundial de açúcar, café, suco de laranja, etanol de cana-de-açúcar e de produtos do complexo soja (farelo, óleo e soja em grãos). O setor agropecuário tem boa representatividade nas exportações brasileiras, sendo as commodities agrícolas os principais produtos da pauta de exportação do país, contribuindo significativamente para o saldo positivo da balança comercial do país.

As exportações do agronegócio em 2011 alcançaram US \$94,5 bilhões, representando 36,9\% do total das exportações brasileiras (SECEX/ MDIC, 2012). Os produtos dos complexos soja (farelo, óleo e grão) e do sucroalcooleiro (açúcar e álcool) assumiram a liderança do ranking de produtos desta categoria, com valores de exportação de US $\$ 24,1$ e US $\$ 14,9$ bilhões, respectivamente, sendo o continente asiático o principal destino dos produtos exportados (SECEX/MDIC, 2012). 
A logística desempenha um papel importante nas cadeias de suprimentos de produtos agrícolas, principalmente naquelas em que o foco é a exportação, devido a motivos como a perecibilidade dos produtos, que pode gerar perdas na sua qualidade com o passar do tempo; o baixo valor agregado, que dificulta a diluição dos custos fixos da logística em comparação aos produtos e ao alto valor agregado; a necessidade de especialização de armazéns e terminais portuários; e a existência de diversos elos ao longo da cadeia de suprimentos.

Com base na situação brasileira atual das cadeias de suprimentos de produtos agrícolas, caracterizada pela falta de coordenação entre os agentes da cadeia e por marcantes efeitos de uma infraestrutura deficitária, verifica-se a necessidade da análise dos principais desafios (FAÇANHA; SILVA; FELDMANN, 2009, CAIXETA FILHO, 2010) que o país precisa encarar, para que se mantenha como um dos principais players na produção e exportação de produtos agrícolas em nível mundial. A partir desta análise, tornar-se-á possível a sugestão de ações para superar tais desafios.

As principais questões a serem analisadas neste artigo são: Quais os principais desafios das cadeias de produtos agrícolas exportados pelo Brasil que podem influenciar na competitividade do país no longo prazo? Quais ações podem ser tomadas a fim de preparar o país para enfrentar os desafios?

Este artigo busca analisar e discutir os principais desafios do Brasil em relação à logística de produtos agrícolas, propondo soluções para eles, com ênfase nas cadeias de exportação. Os resultados esperados se referem à identificação de gargalos nos mercados de produtos agrícolas que podem impactar na competitividade do país e à elaboração de propostas para um melhor posicionamento do Brasil em face desses problemas. A fim de abordar esses assuntos, as seções desta pesquisa estão distribuídas em introdução, revisão de literatura, procedimentos metodológicos, análise e discussão dos resultados e considerações finais. 


\section{Revisão de literatura}

A revisão de literatura será apresentada nas subseções logística, cadeias de suprimentos e o agronegócio brasileiro e a importância da rastreabilidade de produtos agrícolas.

\subsection{Logística, cadeia de suprimentos e o agronegócio brasileiro}

Uma das primeiras definições de logística moderna é a proposta por Daskin (1985), que a considera a ciência responsável por estudar e propor soluções para a movimentação de diferentes insumos e produtos entre empresas e/ou consumidores, buscando a satisfação das necessidades de localização, quantidade, tempo e qualidade dos produtos, com o menor custo possível. Na literatura recente, as definições de logística propostas por Ballou (2006) e Bowersox et al. (2002) são semelhantes às de Daskin (1985), porém o fator sustentabilidade é adicionado por esses autores, mostrando a necessidade de se considerar a destinação do produto ao final de sua vida útil (logística reversa).

A logística é uma das partes integrantes do conceito de cadeia de suprimentos (supply chain). Define-se cadeia de suprimentos como uma rede que engloba todas as empresas e agentes envolvidos, tanto de forma direta quanto indireta, no atendimento da demanda dos consumidores de um determinado produto (CHOPRA; MEINDL, 2010). No que diz respeito às cadeias de suprimentos agroalimentares, as atividades de transporte e de armazenamento, se forem planejadas e operadas de maneira integrada, podem resultar em benefícios claros e contabilizáveis. Essas atividades são consideradas, nesta pesquisa, as principais funções logísticas pelo seu impacto no custo total. O impacto dessas funções é mais significativo caso sejam consideradas as perdas pós-colheita originadas pelo transporte inadequado aliado à perecibilidade de determinados produtos agrícolas (CAIXETA FILHO, 2010). 
A Figura 1 esquematiza a estrutura geral do agronegócio brasileiro em termos de sua configuração produtiva, iniciando com a produção e distribuição de insumos utilizados na etapa de produção da cadeia de suprimentos, formada pelos setores da agricultura e pecuária, agroindústria e energia. Por fim, na etapa de comercialização, os produtos são distribuídos para atacadistas, cooperativas, exportadores, varejistas, até chegarem ao consumidor final. Estudo da Associação Nacional dos Usuários de Transporte de Carga (ANUT, 2008) e dados do Ministério do Desenvolvimento, Indústria e Comércio Exterior (SECEX/MDIC, 2012) sinalizam que o Brasil ampliou sua participação no comércio mundial de produtos agrícolas.

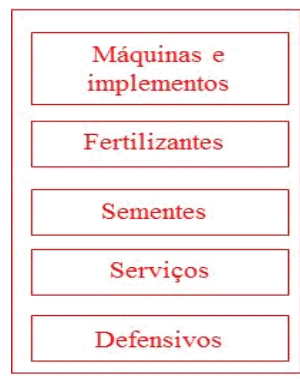

Insumos

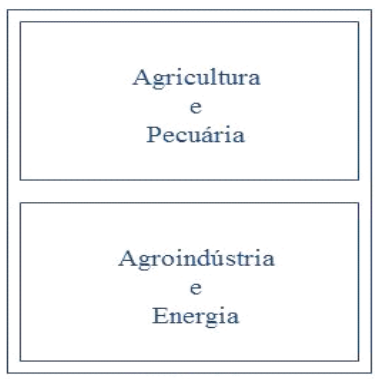

Produção

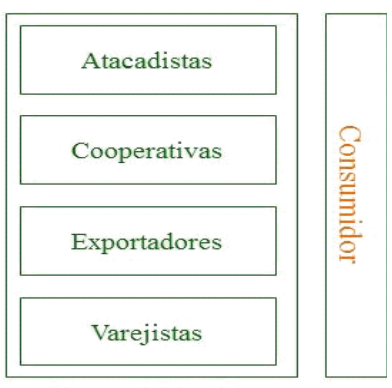

Comercialização

Figura 1: Estrutura do agronegócio brasileiro.

Fonte: Elaborada pelos autores com base em ANUT (2008).

Com base na pesquisa publicada no Anuário Exame (2008), os respondentes consideraram a infraestrutura logística o principal entrave ao desenvolvimento do agronegócio brasileiro, sendo apontada por $76 \%$ dos agentes do setor agrícola. Também podem ser citados outros resultados como carga tributária (75\%), taxa de câmbio (49\%), barreiras comerciais/protecionismo (36\%), questões ambientais (19\%) e questões sanitárias (12\%). Em 2009, um estudo semelhante foi realizado pelo Fórum Econômico Mundial (WEC, 2009), tendo 15\% dos entrevistados apontado a falta de infraestrutura adequada o principal problema brasileiro para a realização de negócios com o mercado externo. 
No Brasil, segundo um levantamento feito pelo Instituto de Logística e Supply Chain (ILOS, 2010), o custo logístico total representa 11,6\% do PIB nacional, $60 \%$ desse percentual correspondendo a gastos com transporte, $30 \%$, a gastos com estoques, e $10 \%$, a gastos administrativos e com a armazenagem de produtos. Nos Estados Unidos, o custo total representa $8,7 \%$ do PIB do país.

Num cenário logístico competitivo e com inserção internacional, o país deve ter como objetivo o equilíbrio da matriz de transportes, considerando os diversos tipos de modais; o fomento de parcerias entre iniciativas públicas e privadas, utilizando o exemplo das concessões em infraestrutura logística (estradas, portos, aeroportos e foco no transporte multimodal); e o reforço legal e regulatório do setor logístico com ação governamental (FAÇANHA et al., 2010). Nesse contexto, destaca-se o impacto dos diversos stakeholders das cadeias, considerando para o caso logístico, principalmente, a presença do governo e da iniciativa privada.

Façanha et al. (2010) evidenciam que os principais motivos do baixo nível de eficiência do transporte de cargas no Brasil são: desbalanceamento da matriz de transportes (necessidade de aumento do uso dos modais ferroviário e hidroviário para redução dos gases do efeito estufa e diminuição nos gastos com transporte de produtos), legislação e fiscalização inadequadas (principalmente, em relação ao transporte rodoviário de cargas e à necessidade de revisão do ICMS estadual e interestadual), deficiência da infraestrutura de apoio e insegurança nas vias. Todos esses desafios estão presentes nas cadeias de produtos agrícolas, porém têm seu efeito ampliado devido à perecibilidade dos produtos, à exigência de rastreabilidade e à vasta gama de produtos e formas de transporte.

\subsection{As cadeias de suprimentos agrícolas e a rastreabilidade}

As cadeias de suprimentos de produtos agrícolas englobam diversos agentes: produtores de insumos, fazendas, unidades de armazenamento, 
unidades de processamento, terminais de transbordo e portuários, prestadores de serviços (transportadores rodoviários, ferroviários, marítimos, despachantes aduaneiros, empresas de seguros e traders) (CHOPRA; MEINDL, 2010; CAIXETA FILHO, 2010) entre outros.

A Figura 2 apresenta um esquema de cadeias agrícolas de granéis sólidos voltados à exportação, casos da soja em grãos, do milho e do açúcar. No caso do açúcar, é necessária a passagem por uma unidade de processamento, denominada usina sucroalcooleira. Nas cadeias de soja e milho, por sua vez, a maior parte dos produtos exportados é na forma a granel (sem processamento). Apesar de ocorrer em menor quantidade, há a possibilidade de o processamento ser feito antes do embarque ao porto de destino, sendo definido pelo comprador e não pelo exportador.

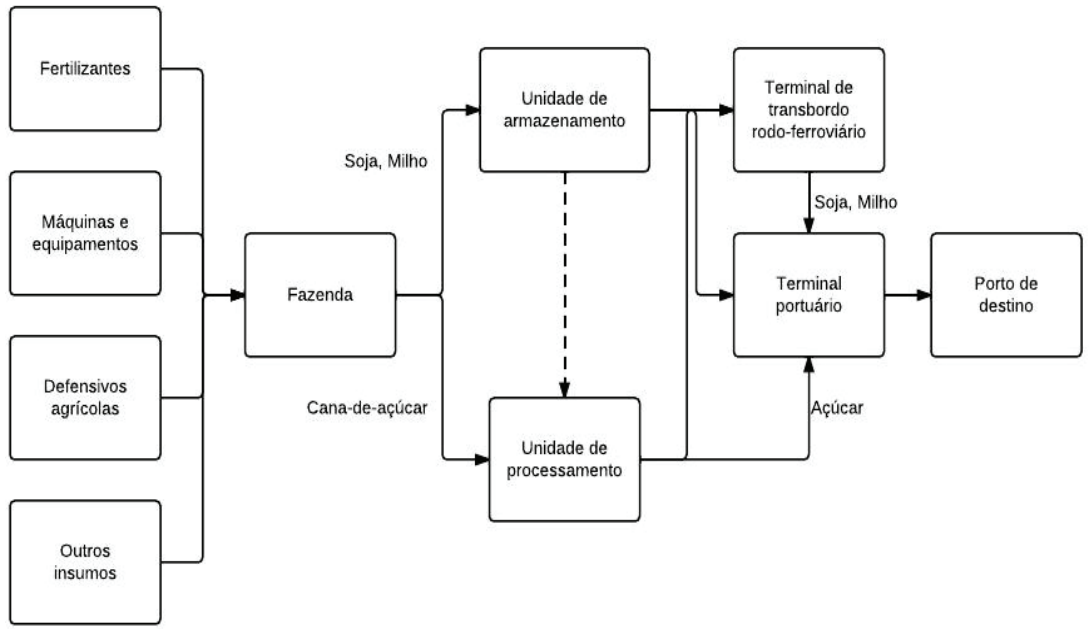

Figura 2: Cadeias de suprimentos de soja, milho e açúcar (voltadas à exportação).

Fonte: Elaborada pelos autores (2012). 
Ao considerar um produto específico, a cadeia assume uma configuração própria. No estudo de qualquer cadeia, os fluxos de produto, dinheiro e informações devem ser observados (CHOPRA; MEINDL, 2010; BOWERSOX et al., 2002; BALLOU, 2006). Nesse contexto, outro fator primordial é a rastreabilidade, ou seja, a existência de um sistema que permita a qualquer envolvido na cadeia saber a localização e os processos pelos quais um produto passou até determinado momento em tempo real (JURAN; GODFREY, 1999). Atualmente, a rastreabilidade é uma exigência dos consumidores, bem como de atacadistas e varejistas (CHOPRA; MEINDL, 2010).

Ao longo das duas últimas décadas, a União Europeia criou uma série de regulamentações e boas práticas em relação à qualidade dos alimentos e a questões relacionadas à rastreabilidade de produtos perecíveis (KELEPOURIS et al., 2007). O principal fator que ocasionou essa preocupação com a rastreabilidade de produtos, segundo os autores, foi a crise da encefalopatia espongiforme bovina no continente europeu.

Outros exemplos de rastreabilidade em cadeias agrícolas podem ser citados, como o caso da cadeia vitivinícola. Gogliano Sobrinho (2008) desenvolveu um trabalho pioneiro no Brasil para essa cadeia, com aplicação de um sistema de informações focado na rastreabilidade das uvas e vinhos que permite, por meio do uso de redes de sensores sem fio, construir um banco de dados com o histórico de todas as suas etapas, disponibilizando suas informações na web.

Em 2008, a Associação Nacional dos Usuários do Transporte de Carga (ANUT) fez uma estimativa da movimentação de cargas de produtos agropecuários no Porto de Santos/SP, baseada nas séries históricas de dados de movimentação de produtos, constatando que, entre 2007 e 2023 (Tabela 1), ocorrerão importantes incrementos na movimentação de soja, fertilizantes, açúcar, etanol, celulose e carne. O destaque é dado para soja, etanol e carne, pois esses produtos apresentam estimativas de crescimento de movimentação acima de $200 \%$ no período considerado. 
Tabela 1: Previsão da Evolução de Movimentação de Produtos Agrícolas no Porto de Santos

\begin{tabular}{|c|c|c|c|}
\hline Produto & $\mathbf{2 0 0 7}$ & $\mathbf{2 0 2 3}$ & Variação (\%) \\
\hline Soja [E] & 7.177 & 21.683 & $202 \%$ \\
\hline Fertilizante [I] & 3.118 & 6.375 & $104 \%$ \\
\hline Açúcar [E] & 14.091 & 26.400 & $87 \%$ \\
\hline Etanol [E] & 1.963 & 6.295 & $221 \%$ \\
\hline Celulose [E] & 1.005 & 1.400 & $39 \%$ \\
\hline Carne [E] & 1.491 & 4.593 & $208 \%$ \\
\hline Outros*[E/I] & 5.616 & 4.053 & $-28 \%$ \\
\hline Total & 34.461 & 70.799 & $105 \%$ \\
\hline
\end{tabular}

Fonte: ANUT (2008).

Notas: [E] Exportação; [I] Importação. (*) Outros: trigo, milho e café.

Um fato não considerado na análise da ANUT (2008) foi a formação de filas nos portos, que atualmente ocorrem com frequência. Um dos principais fatores que levam à formação de filas é a falta de infraestrutura dos terminais portuários. Em 2011, as filas de caminhões no Porto de Paranaguá chegaram a 17 km (BRASIL, 2011). Essa ineficiência leva tanto a um aumento dos custos de frete, quanto a uma maior complexidade nas cadeias logísticas, aumentando o tempo em trânsito do produto e diminuindo a confiabilidade nos embarques, o que atinge negativamente a competitividade do país.

\section{Metodologia}

Esta seção trata dos procedimentos metodológicos utilizados ao longo deste estudo (GIL, 2010). De acordo com os objetivos mais gerais, o estudo se destaca como uma pesquisa exploratória e, num segundo momento, descritiva. No que tange aos métodos empregados, a natureza dos dados é de caráter qualitativo. 
O delineamento desta pesquisa se configura a partir das pesquisas bibliográfica e documental (GIL, 2010). Com os dados e informações obtidos das duas pesquisas mencionadas, a análise é feita em relação aos principais gargalos observados nas cadeias agrícolas, tendo em vista as tendências de aumento dos custos de produção e a demanda por rastreabilidade. Dessa forma, serão feitas considerações para os gargalos observados nas cadeias de suprimentos agrícolas.

\section{Resultados e discussão}

A discussão está organizada na forma de considerações a serem feitas sobre os gargalos observados nas cadeias de suprimentos agrícolas: diferenças entre as cadeias de suprimentos agrícolas; necessidade de rastreabilidade; e infraestrutura atual face às necessidades dos produtos.

\subsection{Considerações em relação às cadeias de suprimentos agrícolas}

Há uma necessidade de que as diferentes cadeias de produtos agrícolas sejam analisadas separadamente, devido às características intrínsecas de cada produto. Também se faz necessário analisar a influência da sobreposição de parte das cadeias, principalmente, no que diz respeito ao uso de equipamentos de transporte semelhantes ao longo do ano. Isso pode ser exemplificado pelos dados de fretes mensais desses produtos (ESALQ-LOG, 2011), os quais demonstram que produtos como soja e açúcar influenciam os fretes um do outro ao longo do ano, pelo fato de utilizarem os mesmos tipos de caminhão.

A classificação das diferentes cadeias de produtos agrícolas sugerida neste artigo, baseada nos conceitos citados ao longo do estudo e levando em consideração os efeitos da sobreposição de cadeias, pode ser feita assim: produtos transportados em sacas, produtos transportados em contêineres e produtos transportados a granel. 
A elaboração de soluções para cada uma das categorias melhoraria a cadeia de suprimentos dos produtos agrícolas para exportação. Os autores propõem a elaboração de medidas gerais para as cadeias de produtos em sacas, produtos em contêineres e produtos a granel. Após essa etapa, é possível otimizar cada cadeia considerando o produto específico de cada uma. Acredita-se que essa abordagem possa ajudar o país a superar o desafio da necessidade de um aumento da eficiência de terminais portuários e do uso de diferentes modais, aumentando a competitividade dos produtos agrícolas brasileiros no mercado mundial.

Para Goetschalckx et al. (2002), um dos grandes problemas das cadeias de suprimentos globais é a forma como é feita sua otimização. Isso pode ser exemplificado pela falta de planejamento integrado de maximização de lucros que considere custos de transferência, flutuação cambial e análise de múltiplos períodos (GOETSCHALCKX et al., 2002). Assim, é necessário considerar não somente os aspectos das cadeias de suprimentos dentro de cada país, mas também a interação entre as cadeias de diversos países.

O fato de não haver uma metodologia preestabelecida que permita otimizar as cadeias complexas, que envolvem exportação e importação de produtos, integrando as cadeias de suprimentos de diversos países, é um problema no planejamento das cadeias agrícolas brasileiras. Isso decorre, principalmente, do fato de as grandes multinacionais, que atuam como traders no mercado internacional, terem locais de produção, processamento e focos de demanda em diversos países, originando diversas possibilidades de fluxos. Como consequência, torna-se insuficiente para que possa haver a otimização da cadeia e, assim, a minimização dos custos de frete de uma cadeia agrícola, como foi sugerido pelos trabalhos acadêmicos (CHOPRA; MEINDL, 2010; BALLOU, 2006; BOWERSOX et al., 2002; GOETSCHALCKX et al., 2002; CAIXETA FILHO, 2010; AHUMADA; VILLALOBOS, 2009).

O processo de modelagem matemática visando à otimização de cadeias agrícolas começou no Brasil há alguns anos, sendo que grande parte dos tomadores de decisões das cadeias considera apenas fatores qualitativos 
na definição de rotas e localização de unidades (CAIXETA FILHO; GAMEIRO, 2001). Mesmo quando a otimização é utilizada, ela não foca a minimização dos custos de toda a cadeia, mas sim a minimização dos custos de apenas um dos elos. O elo favorecido, no caso da carne bovina, é o dos abatedouros. No caso dos granéis sólidos como milho, soja e açúcar, esse elo é representado pelas grandes multinacionais que atuam como traders no mercado internacional. No caso de suco de laranja, o elo favorecido é o das indústrias produtoras de suco.

Para superar esse desafio de metodologia de análise das cadeias e sua aplicação na otimização delas, os autores sugerem que, após a classificação sugerida no item anterior, as cadeias de cada produto sejam analisadas e otimizadas, utilizando softwares específicos como o GAMS (General Algebraic Modeling System). O processo deve ser contínuo, com revisões periódicas dos dados utilizados e dos resultados obtidos em conjunto com ofeedback obtido pelos diferentes elos da cadeia. Para que essa etapa seja eficiente, há a necessidade de se aumentar a coordenação entre os elos da cadeia (fomento da cooperação).

\subsection{Considerações sobre a rastreabilidade nas cadeias agrícolas}

A rastreabilidade agrícola é baseada na documentação, na manutenção, no arquivamento das informações e na sua utilização ao longo do processo. Sistema esse que possibilita ao consumidor ou a outro interessado as informações necessárias para conhecer a história de um produto, bem como auxiliar correções no processo em relação à qualidade e à segurança deste mesmo produto (OPARA, 2003).

Muito em breve, todos os produtos exportados exigirão sistemas de rastreabilidade. A pouca coordenação observada nas cadeias de produtos agrícolas voltados para exportação torna difícil o estabelecimento de sistemas de rastreabilidade de alta qualidade (GOETSCHALCKX et al., 2002). A falta de rastreabilidade observada nas cadeias de produtos agrícolas é um problema de impacto imediato para o setor de alimentos de 
maior valor agregado, caso das carnes e frutas (DORR; GROTE, 2009). Após sua implementação, a divisão dos benefícios proporcionados por um sistema de rastreabilidade, com tecnologias que permitam menores gastos com mão de obra e informações de melhor qualidade, também é de difícil realização.

Nesse contexto, para que o país enfrente o desafio da falta de rastreabilidade de seus produtos agrícolas, faz-se necessário um estudo de cada cadeia produtiva em específico. Após essa etapa, melhorar a coordenação entre os diferentes elos se torna fundamental, o que pode ser observado em ações governamentais como o Fórum de Competitividade da Indústria de Carnes (SECEX/MDIC, 2005) e as Câmaras Setoriais das diferentes cadeias agrícolas.

Depois de concluídas essas etapas, é possível construir um modelo de sistema de rastreabilidade para cada produto, que permita a obtenção de informações com relação ao histórico e à localização dos produtos, em tempo real, por qualquer agente da cadeia. Isso atenderá a uma exigência dos consumidores e resultará em maior eficiência no uso de ativos de transporte e armazenagem, planejamento mais adequado dos processos de produção e distribuição e em menor possibilidade de ocorrência de falhas humanas.

\subsection{Considerações em relação à infraestrutura atual}

Uma das principais dificuldades que o Brasil enfrenta em termos logísticos é o fato de sua matriz de transportes ser, em sua maioria, rodoviária. Com base nos dados da ANUT (2008), 58\% da matriz de transportes do país corresponde ao modal rodoviário, tendo as ferrovias uma participação de $25 \%$. Esses números podem ser questionados, pois o transporte de produtos com movimentação significativa é feito pelo modal ferroviário, casos do cimento e do minério de ferro. Há uma grande possibilidade de que o modal rodoviário seja mais concentrado do que se pode observar nos dados apresentados. 
A Pesquisa de Rodovias da CNT 2010 (CNT, 2011) mostra que o estado atual das rodovias é preocupante. Dos $90.945 \mathrm{~km}$ de rodovias do país, $41,20 \%$ delas foram classificadas como boas ou ótimas, englobando vias com sinalização adequada, pavimentação de boa qualidade e geometria da via adequada para transportes de passageiros e de carga. Verifica-se que a maior parte das rodovias em boa qualidade se localiza no estado de São Paulo e, dessa parcela, uma quantia considerável está sob regime de concessão de pedágios (CNT, 2011).

Devido à falta de eficiência e/ou de equipamentos adequados, os terminais portuários não estão adequados para a movimentação atual de produtos, gerando filas e aumento dos custos de frete para os produtos que são exportados. Com o aumento da demanda mundial, a quantidade exportada pelo país tende a crescer e, caso os problemas com os portos não sejam sanados, serão fatores limitantes da quantidade escoada, diminuindo a competitividade do país.

A solução proposta para superar esse gargalo é o uso de parcerias públicoprivadas (FAÇANHA et al., 2010). Assim, os investimentos necessários para a recuperação da malha viária atual poderiam ser captados. Após a recuperação das rodovias e ferrovias de maior utilização no escoamento de produtos agrícolas, tornar-se-ia relevante um programa consistente e permanente de manutenção das vias, com diálogo entre os representantes públicos e os elos das cadeias. Dessa forma, os desafios - separação das cadeias em diferentes categorias, estudo, análise e otimização das cadeias de cada produto, sistema de qualidade de rastreabilidade implementado - seriam devidamente analisados.

\section{Considerações finais}

O Brasil tem uma grande chance de se estabelecer como o principal fornecedor mundial de produtos agrícolas, tanto os de baixo quanto os de alto valor agregado. Para isso, é necessário sanar uma série de gargalos que impedem que programas de rastreabilidade sejam implementados 
de forma satisfatória, o que é exigido por consumidores internacionais. Assim, este artigo buscou identificar os gargalos e propor ações para melhorar a situação observada vista atualmente.

Foram identificados grandes desafios às cadeias de suprimentos de produtos agrícolas brasileiros: necessidade de análise das cadeias agrícolas; necessidade de coordenação entre os elos de cada cadeia; melhoria nas metodologias utilizadas para otimização das cadeias agrícolas, nas quais cada elo tenta maximizar seu próprio lucro ou eficiência, em detrimento dos resultados da cadeia como um todo; necessidade da existência de sistemas de rastreabilidade satisfatórios que englobem toda a cadeia; e considerações em relação à infraestrutura do atual agronegócio brasileiro.

Visando a superar os desafios identificados, foram sugeridas as propostas: separação dos produtos por categorias e análise das mesmas; incentivos governamentais para a coordenação das cadeias específicas de cada produto; utilização de softwares de otimização para aumentar sua eficiência; elaboração de um sistema de rastreabilidade para cada cadeia, que permita o fácil acesso por todos os envolvidos na cadeia; criação de um programa governamental para recuperar a malha viária e fazer sua manutenção periodicamente, de modo viável, por meio do uso de parcerias público-privadas. 


\section{Referências}

ANUT - Associação Nacional dos Usuários do Transporte de Carga. Transporte - desafio ao crescimento do agronegócio brasileiro. Rio de Janeiro, 2008. Disponível em: <http://www.anut.org.br/Anut/ estudos_trabalhos.asp>. Acesso em: 11 dez. 2011.

BALLOU, R. H. Gerenciamento da cadeia de suprimentos. Porto Alegre: Bookman, 2006.

BOWERSOX, D. J.; CLOSS, D. J.; COOPER, M. B. Supply chain logistics management. New York: McGraw-Hill Publisher, 2002.

BRASIL - Ministério da Agricultura. Estatísticas. 2012. Disponível em: $<$ http://www.agricultura.gov.br/vegetal/estatisticas $>$. Acesso em: 06 jan. 2012.

BRASIL - Secretaria de Portos. Fila de caminhões no Porto de Paranaguá chega a $17 \mathrm{~km}$. 2011. Disponível em: <http://www. portodesantos.com.br/clipping.php?idClipping $=17468>$. Acesso em: 20 jun. 2011.

CAIXETA FILHO, J. V. Logística para a agricultura brasileira. RBCE, v. 25, n. 103, p. 18-30, abr.jun. 2010.

CAIXETA FILHO, J. V.; GAMEIRO, A. H. Transporte e logística em sistemas agroindustriais. São Paulo: Atlas, 2001.

CHOPRA, S.; MEINDL, P. Supply chain management. New Jersey: Pearson Education, 2010.

CNT - Confederação Nacional do Transporte. Pesquisa CNT de rodovias 2010. Brasília, 2011. Disponível em: <http://www.cnt.org.br/>. Acesso em: 14 jun. 2011. 
DASKIN, M.S. Logistics: an overview of the state of the art and perspectives on future research, Transportation Research, v.19, n.5-6, pp. 383-393, 1985.

DORR, A. C.; GROTE, U. O papel da certificação na fruticultura brasileira. Rev. econ. contemp., v. 13, n. 3, p. 539-571, 2009.

ESALQ-LOG - Grupo de Pesquisa e Extensão em Logística Agroindustrial. Sistema de informações de fretes (Sifreca). Piracicaba, 2011.

FAÇANHA, S. L. O.; SILVA, M. A.; FELDMANN, P. R. Tendências e desafios brasileiros na logística globalizada do séc. XXI. In: SEMEAD, 13, 2010, Anais... São Paulo: FEA-USP, 2010.

GIL, A. C. Como elaborar projetos de pesquisa. São Paulo: Atlas, 2010.

GOETSCHALCKX, M.; VIDAL, C. J.; DOGAN, K. Modeling and design of global logistics systems: a review of integrated strategic and tactical models and design algorithms. European Journal of Operational Research, v. 143, p. 1-18, 2002.

GOGLIANO SOBRINHO, O. Modelagem de um sistema de informação para rastreabilidade na indústria vinícola baseado em uma arquitetura orientada a serviços. Dissertação (Mestrado em Engenharia Elétrica) - Universidade de São Paulo, São Paulo, 2008.

ILOS - Instituto de Logística e Supply Chain. Custos logísticos no Brasil. Rio de Janeiro, 2010.

JURAN, J. M.; GODFREY, A. B. Juran's quality handbook. New York: McGraw-Hill, 1999.

KELEPOURIS, T. et al. RFID-enabled traceability in the food supply chain. Industrial Management \& Data Systems, v. 107, n. 2, pp. 183200, 2007. 
OPARA, L. U. Traceability in agriculture and food supply chain: a review of basic concepts, technological implications, and future prospects. Food, Agriculture \& Environment, v.1, pp. 101-106, 2003.

REVISTA EXAME. Revista Anuário Exame: agronegócio 2008/2009. São Paulo: Abril, 2008.

SECEX/MDIC - Secretaria de Comércio Exterior/Ministério do Desenvolvimento, Indústria e Comércio Exterior. Fórum de competitividade da indústria de carnes. Brasília, 2005.

. Aliceweb. 2012. Disponível em: $<$ http://aliceweb. desenvolvimento.gov.br/>. Acesso em: 25 jan. 2012.

SILVA, R. F.; CAIXETA FILHO, J. V.; ZUCCHI, J. D. Exportação de carne bovina: gargalos portuários. Agroanalysis, v. 30, p. 18-19, 2010.

WEC - World Economic Forum. The Brazil competitiveness report 2009. Genebra, 2009. 